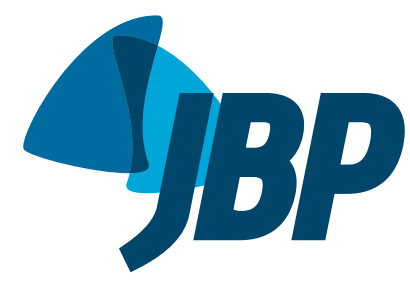

1. Hospital Universitario San Ignacio Facultad de Medicina, Pontificia Universidad Javeriana, Bogotá Colombia.

2. Departamento de Medicina Interna, Facultad de Medicina, Pontificia Universidad Javeriana, Bogotá, Colombia.

3. Departamento de Epidemiología Clínica y Bioestadística, Facultad de Medicina, Pontificia Universidad Javeriana, Bogotá, Colombia.

4. Facultad de Odontología, Facultad de Medicina, Pontificia Universidad Javeriana, Bogotá, Colombia.

a. iD http://orcid.org/0000-0002-2536-4471

b. (iD http://orcid.org/0000-0001-6528-4268

c. (iD http://orcid.org/0000-0001-5576-9341

d. (iD) http://orcid.org/0000-0003-1803-9141

Submitted: 16 March 2016

Accepted: 26 February 2017.

Study carried out at the Hospital

Universitario San Ignacio, Facultad de

Medicina, Pontificia Universidad Javeriana

Bogotá, at the Instituto Neumológico del

Oriente, Bucaramanga, and at Respire

Previcare, Santa Marta, Colombia.

\section{Sleep characteristics in an adult with sleep complaints in three cities at different altitudes}

\author{
Julio Cesar Castellanos-Ramírez ${ }^{1, a}$, Alvaro J Ruíz ${ }^{2,3, b}$, \\ Patricia Hidalgo-Martínez ${ }^{1,2, c}$, Liliana Otero-Mendoza ${ }^{4, \mathrm{~d}}$
}

\begin{abstract}
Sleep studies conducted at an altitude that is different from the home altitude can yield misleading results regarding the severity of obstructive sleep apnea (OSA). The objective of the present study was to determine the sleep characteristics of a patient undergoing polysomnography (PSG) in three Colombian cities at different altitudes (Bogotá, at 2,640 $\mathrm{m}$ above sea level [ASL]; Bucaramanga, at $959 \mathrm{~m} \mathrm{ASL}$; and Santa Marta, at $15 \mathrm{~m} \mathrm{ASL).}$ The patient was an obese man with diabetes and suspected OSA. All PSG recordings were scored and interpreted in accordance with American Academy of Sleep Medicine criteria. In Bogotá, PSG revealed moderate OSA (an apnea-hypopnea index [AHI] of 21 events/h); in Bucaramanga, PSG revealed increased upper airway resistance (an AHI of 2 events/h); in Santa Marta, PSG revealed mild OSA (an AHI of 7 events/h). The reduction in the $\mathrm{AHI}$ was predominantly a reduction in hypopneas and obstructive apneas. The respiratory events were shorter in duration in the city at an intermediate altitude. Given that the AHI varied widely across cities, we can assume that the patient is normal or has moderate OSA depending on the city where he is. Central apneas were found to have no influence on the AHI.
\end{abstract}

Keywords: Sleep apnea, obstructive; Polysomnography; Altitude.

\section{INTRODUCTION}

Sleep disorders have a substantial impact on the quality of life of patients and on their work performance. ${ }^{(1)}$ The prevalence of sleep complaints in Colombia is $59.6 \%$. $^{(2,3)}$ Among sleep disorders, sleep-disordered breathing has the most serious and deleterious health consequences, and studies have shown substantial increases in its prevalence. ${ }^{(4,5)}$

Multiple studies have shown that as the altitude increases, so does the possibility of disorders. These disorders have been associated with decreased $\mathrm{PaO}_{2}$ resulting from changes in altitude, although in some cases evidence suggests that they are more closely related to hypoxic changes than to reduced atmospheric pressure (AP). ${ }^{(6)}$ However, what is the effect of altitude descent on sleep-disordered breathing? Could it be explained by changes in three atmospheric variables, namely air density (and therefore viscosity through a critically narrowed upper airway), oxygen content, and barometric pressure or external compressive effect? ${ }^{(7)}$ In an attempt to answer these questions, we conducted three polysomnographic studies on a patient residing in the city of Bogotá, Colombia. Each study was conducted in a different city in Colombia, namely Bogotá (at 2,640 $\mathrm{m}$ above sea level [ASL]), Bucaramanga (at $959 \mathrm{~m} \mathrm{ASL}$ ), and Santa Marta (at $15 \mathrm{~m} \mathrm{ASL}$ ), the recordings being scored and interpreted in accordance with American Academy of Sleep Medicine criteria. ${ }^{(8)}$

\section{CASE REPORT}

We report the case of a 57-year-old male public health official originally from Bogotá and undertaking extensive domestic and international travel. His relevant medical history included diet-controlled diabetes mellitus-he had been diagnosed with diabetes mellitus 10 years prior-and tonsillectomy during childhood. At this writing, the patient was a current smoker (with a smoking history of 6 pack-years). In addition to having reported no medication use, he reported being unable to have a regular diet during his travels, his diet usually consisting of sandwiches and soup. He reported drinking alcohol only on special occasions.

Correspondence to:

Patricia Hidalgo Martínez, Carrera 7, no. 40-62, Cundinamarca, Bogotá, Colombia.

Tel.: 57 5946161.E-mail: phidalgo@husi.org.co or hidalgop@javeriana.edu.co

Financial support: This study received financial support from the Colombian Departamento Administrativo de Ciencia, Tecnología e Innovación (Colciencias, Administrative

Department of Science, Technology and Innovation; Grant no. 369). 
The patient reported snoring, daytime sleepiness, fatigue, and morning headaches. Before the three polysomnographic recordings, he described his sleep as being generally very good. Upon physical examination, the patient was noted to be $1.74 \mathrm{~m}$ tall, his weight, body mass index, waist circumference, and neck circumference being $94 \mathrm{~kg}, 31.04 \mathrm{~kg} / \mathrm{m}^{2}, 110$ $\mathrm{cm}$, and $47 \mathrm{~cm}$, respectively. The remainder of the physical examination was unremarkable. His Epworth Sleepiness Scale score was 11.

The polysomnographic study conducted in Bogotá showed a sleep latency of $4 \mathrm{~min}$ and a sleep efficiency of $82 \%$. There was an increase in non-rapid eye movement (NREM) stage 1 sleep (to $24 \%$ of total sleep time) and a decrease in rapid eye movement (REM) sleep (to $18 \%$ of total sleep time). The apnea-hypopnea index (AHI) was 21 events per hour of sleep, indicating moderate supine-dependent sleep apnea. Respiratory events included primarily hypopneas, which were more frequent during NREM sleep. The longest event lasted 25 s. Snoring was observed. Only 6 central apneas without periodic breathing were observed (Table 1). The patient had no significant periodic leg movements in sleep. Most arousals were related to respiratory events, with a rate of 3 per hour. Mean waking oxygen saturation was $86 \%$, having decreased to $74 \%$ during events.

The polysomnographic study conducted in Bucaramanga showed a slightly prolonged sleep latency (of $26 \mathrm{~min}$ ) and a decreased sleep efficiency (of 75\%). There was an increase in NREM stage 1 sleep (to $20 \%$ of total sleep time). REM sleep accounted for $23 \%$ of total sleep time. The AHI was 2 events per hour of sleep. There were respiratory effort-related arousals and flattening of the respiratory curve, indicating airflow limitation (Table 1). Snoring was observed. No central events were observed. The patient had 10 arousals per hour. The longest event lasted $18 \mathrm{~s}$. There were no periodic leg movements in sleep. Mean waking oxygen saturation was $94 \%$, having decreased to $86 \%$ during sleep.

The polysomnographic study conducted in Santa Marta showed a sleep latency of $11 \mathrm{~min}$ and a sleep efficiency of $81 \%$. There were increases in NREM stage 1 sleep (to $19 \%$ of total sleep time) and REM sleep (to $35 \%$ of total sleep time). There were 6 central apneas without periodic breathing (Table 1). The AHI was 7 events per hour of sleep, indicating mild, predominantly supine-dependent sleep apnea. Respiratory events included primarily obstructive apneas, predominantly during NREM sleep. Snoring was observed. The longest event lasted $23 \mathrm{~s}$. The patient had no significant periodic leg movements in sleep. Mean waking oxygen saturation was $94 \%$, having decreased to $88 \%$ during respiratory events. The patient had 4 arousals per hour.

\section{DISCUSSION}

Although we expected a linear relationship between sleep apnea and altitude, we found that the city in which the patient showed the lowest AHI was at an intermediate altitude (i.e., Bucaramanga, at $959 \mathrm{~m}$ ASL). In Bogotá, which is the city at the highest altitude (2,640 $\mathrm{m} \mathrm{ASL})$ and where the patient resided at this writing, polysomnography (PSG) showed moderate

Table 1. Summary of the results.

\begin{tabular}{|c|c|c|c|}
\hline \multirow[t]{4}{*}{ Variable } & \multicolumn{3}{|c|}{ City (altitude) } \\
\hline & $\begin{array}{c}\text { Bogotá } \\
(2,640 \mathrm{~m} \text { ASL) }\end{array}$ & $\begin{array}{l}\text { Bucaramanga } \\
\text { (959 m ASL) }\end{array}$ & $\begin{array}{l}\text { Santa Marta } \\
\text { (15 m ASL) }\end{array}$ \\
\hline & \multicolumn{3}{|c|}{ Date } \\
\hline & February 17, 2014 & October 14, 2014 & August 5, 2014 \\
\hline Weight, kg & 94 & 94 & 94 \\
\hline Sleep efficiency, \% & 82 & 75 & 81 \\
\hline Sleep latency, min & 4 & 26 & 11 \\
\hline REM sleep latency, min & 64 & 53 & 94 \\
\hline NREM stage 1 sleep, \% & 24 & 20 & 19 \\
\hline NREM stage 2 sleep, \% & 46 & 46 & 40 \\
\hline NREM stage 3 sleep, \% & 12 & 11 & 6 \\
\hline REM sleep, \% & 18 & 23 & 35 \\
\hline Central apneas, $\mathrm{n}$ & 6 & 0 & 6 \\
\hline Obstructive apneas, $\mathrm{n}$ & 37 & 11 & 26 \\
\hline Mixed apneas, $n$ & 0 & 0 & 0 \\
\hline Hypopneas, n & 69 & 3 & 6 \\
\hline AHI, events/h & 21 & 2 & 7 \\
\hline Supine AHI, events/h & 39 & 2 & 12 \\
\hline Arousal index, events/h & 3 & 10 & 1 \\
\hline $\mathrm{SpO}_{2}, \%$ & $74-86$ & $86-94$ & $88-94$ \\
\hline Heart rate, bpm & $66-91$ & $67-74$ & $66-70$ \\
\hline
\end{tabular}

ASL: above sea level; REM: rapid eye movement; NREM: non-rapid eye movement; and AHI: apnea-hypopnea index. 
sleep apnea (an AHI of 21 events/h). This could be explained by the acclimatization process, whereby the number of central apneas might decrease and obstructive events might occur. In Bucaramanga, the patient showed increased upper airway resistance, whereas in Santa Marta-the city at the lowest altitude (15 m ASL)-he showed mild sleep apnea (an AHI of 7 events/h). The highest AHI was found in the city at the highest altitude, a finding that is consistent with those of the literature. However, the effect of altitude descent on the $\mathrm{AHI}$ in the present study contrasts with that reported by Patz et al.,(7) who studied 11 patients and found a reduction in the AHI on descent. They found that the reduction in the $\mathrm{AHI}$ was predominantly a reduction in central apneas and hypopneas, which decreased by $70 \%$ and $49 \%$, respectively. ${ }^{(7)}$ In our patient, the reduction in the AHI was due to fewer hypopneas and obstructive apneas, which decreased by $85 \%$ and $71 \%$, respectively. This reduction in hypopneas on altitude descent is consistent with the findings of Patz et al. ${ }^{(7)}$

Our results could be explained by our particular climatic conditions. It has been reported that patients with sleep-disordered breathing exhibit an increased AHI with increasing altitude, and it has been postulated that hypoxic changes are the triggers of this phenomenon, more so than reductions in AP. ${ }^{(6)}$ In a sleep study conducted at $60 \mathrm{~m} \mathrm{ASL}$, the AHI was found to be altered by changes in weather-related AP. ${ }^{(6)}$ The authors of that study concluded that small changes in AP due to weather systems might play an important role in the pathophysiology and diagnosis of obstructive sleep apnea. ${ }^{(6)}$

Unlike Patz et al., (7) we found no significant association between longer lasting events and lower altitudes. In our patient, the duration of the events was similar between the study conducted at the highest altitude and the study conducted at the lowest altitude (25 s vs. $23 \mathrm{~s}$ ), being shortest (18 s) in the study conducted at an intermediate altitude. We expected that, at a lower altitude, it would have taken longer to reach the threshold $\mathrm{SaO}_{2}$ to trigger arousal, leading to a longer apnea. ${ }^{(7)}$

With regard to hypoxemia, we found an inverse linear trend with altitude; values of $82 \%, 86 \%$, and $88 \%$ were found for the highest to lowest altitudes, being similar to those described in the literature. In Bogotá, we found that oxygen saturation remained below $90 \% 80 \%$ of the time, whereas in the other two cities it remained below $90 \%$ only $0.4 \%$ of the time. This finding is very important because of the proposed association between desaturation time and the development of neoplastic lesions in the long term, ${ }^{(9)}$ as well as because of the development of pulmonary hypertension. ${ }^{(10)}$

In all three cities, our patient spent more time in superficial sleep stages ( $24 \%$ of total sleep time in Bogotá, $20 \%$ of total sleep time in Bucaramanga, and $19 \%$ of total sleep time in Santa Marta), showing a downward trend with altitude. Air conditioning was not used in any of the cities, and our country has no seasons. The patient traveled to Bucaramanga on the same day on which PSG was performed and to Santa Marta one day before PSG.

The polysomnographic studies conducted in Santa Marta and Bogotá showed central events without periodic breathing. The types of events observed in our patient (with a predominance of obstructive apneas in Santa Marta and of hypopneas in Bogotá) are similar to those described previously. ${ }^{(11)}$ In a study of sleep disorders in immigrants with and without chronic mountain sickness, hypopnea was found to be the most common event. ${ }^{(11)}$

Our patient had 4 arousals per hour of sleep in Santa Marta, 3 in Bogotá, and 10 in Bucaramanga. It has been reported that an increased AHI does not cause more frequent arousals at high altitudes. ${ }^{(12)}$ This finding is similar to those of the present study. Although our patient showed an arousal rate within normal limits in two cities, this does not rule out the possibility that daytime functioning might be affected. It has been reported that respiratory disorders not accompanied by arousals could impact the quality of sleep and impair reparative processes associated with sleep more than previously believed. ${ }^{(13)}$

Studies examining the presence of sleep apnea at different altitudes have shown decreased oxygen saturation, increased $\mathrm{AHI}$, and decreased slow wave sleep at higher altitudes. Our finding of decreased oxygen saturation is consistent with the literature. ${ }^{(14)}$

From a physiological standpoint, increased sensitivity to $\mathrm{CO}_{2}$ below eupnea leads to $\mathrm{PaCO}_{2}$ levels below the threshold for apnea and causes breathing to stop until $\mathrm{PaCO}_{2}$ rises above the apnea threshold. (15) Given that capnography was unavailable, we were unable to observe that in our patient.

Although no statistically significant differences have been found between high and low altitudes regarding specific sleep stage duration, sleep quality, total sleep time, and sleep efficiency, the number of arousals has been found to have doubled at a high altitude. ${ }^{(16)}$ No changes in the frequency of periodic breathing have been reported, with the exception of isolated central events and a lower mean oxygen saturation at a high altitude. ${ }^{(16)}$

It is of note that the polysomnographic study that we conducted in Bucaramanga showed upper airway resistance syndrome in our patient. This finding is noteworthy because of the ongoing debate regarding this condition and the diagnostic approach to, health implications of, and therapeutic options for it. ${ }^{(17-20)}$ Further comparative studies are needed, especially in Colombia and other countries with similar geographic characteristics, barometric pressure, and climate, in order to provide a better understanding of the characteristics of sleep disorders, improve detection programs, correct disturbances, and provide more treatment options tailored to each individual. 


\section{REFERENCES}

1. Swanson LM, Arnedt JT, Rosekind MR, Belency G, Balkin TJ, Drake C. Sleep disorders and work performance: findings from the 2008 National Sleep Foundation Sleep in America poll. J Sleep Res. 2011;20 (3):487-94. https://doi.org/10.1111/j.1365-2869.2010.00890.x

2. Ruiz A, Sepúlveda MA, Martínez PH, Muñoz MC, Mendoza LO Centanaro OP, et al. Prevalence of sleep complaints in Colombia at different altitudes. Sleep Sci. 2016;9(2):100-5. https://doi. org/10.1016/j.slsci.2016.05.008

3. Ruiz A, Rondon Sepúlveda MA, Franco OH, Cepeda M, Hidalgo Martinez P, Amado Garzón SB, et al. The associations between sleep disorders and anthropometric measures in adults from three Colombian cities at different altitudes. Maturitas. 2016; 94:1-10. https://doi.org/10.1016/j.maturitas.2016.08.013

4. Peppard PE, Young T, Barnet JH, Palta M, Hagen EW, Hla KM Increased prevalence of sleep-disordered breathing in adults. Am Epidemiol. 2013;177(9):1006-14. https://doi.org/10.1093/aje/kws342

5. Otero L, Hidalgo P, González R, Morillo CA. Association of Cardiovascular Disease and Sleep Apnea at Different Altitudes. High Alt Med Biol. 2016;17(4):336-341. https://doi.org/10.1089/ ham.2016.0027

6. Doherty MJ, Youn CE, Haltiner AM, Watson NF. Do weather-related ambient atmospheric-pressure changes influence sleep disordered breathing? J Clin Sleep Med. 2010;6(2):152-6.

7. Patz D, Spoon M, Corbin R, Patz M, Dover L, Swihart B, et al The effect of altitude descent on obstructive sleep apnea. Chest. 2006;130(6):1744-50. https://doi.org/10.1378/chest.130.6.1744

8. American Academy of Sleep Medicine [homepage on the Internet]. Darien, IL: American Academy of Sleep Medicine; 2013 [cited 2016 Feb 1]. The AASM Manual for the Scoring of Sleep and Associated Events: Rules, Terminology and Technical Specifications, Version 2.0.2. Available from: http://www.aasmnet.org/scoringmanual/

9. Campos-Rodriguez F, Martinez-Garcia MA, Martinez M, DuranCantolla J, Peña Mde L, Masdeu MJ, et al. Association between obstructive sleep apnea and cancer incidence in a large multicente Spanish cohort. Am J Respir Crit Care Med. 2013;187(1):99-105. https://doi.org/10.1164/rccm.201209-16710C

10. Kent BD, Mitchell PD, McNicholas WT. Hypoxemia in patients with COPD: cause, effects, and disease progression. Int J Chron Obstruct
Pulmon Dis. 2011;6:199-208.

11. Guan W, Ga Q, Li R, Bai ZZ, Wuren T, Wang J, Yang YZ, et al Sleep disturbances in long-term immigrants with chronic mountain sickness: a comparison with healthy immigrants at high altitude. Respir Physiol Neurobiol. 2015;206:4-10. https://doi.org/10.1016/j resp.2014.11.007

12. Tseng $\mathrm{CH}$, Lin FC, Chao HS, Tsai HC, Shiao GM, Chang SC. Impact of rapid ascent to high altitude on sleep. Sleep Breath. 2015;19(3):819 26. https://doi.org/10.1007/s11325-014-1093-7

13. Stadelmann K, Latshang TD, Tarokh L, Lo Cascio CM, Tesler N Stoewhas AC, et al. Sleep respiratory disturbances and arousals at moderate altitude have overlapping electroencephalogram spectra signatures J Sleep Res. 2014;23(2):463-8. https://doi.org/10.1111/ jsr. 12131

14. Latshang TD, Lo Cascio CM, Stöwhas AC, Grimm M, Stadelmann $\mathrm{K}$, Tesler $\mathrm{N}$, et al. Are nocturnal breathing, sleep, and cognitive performance impaired at moderate altitude (1,630-2,590m)? Sleep. 2013;36(12):1969-76. https://doi.org/10.5665/sleep.3242

15. Javaheri S, Dempsey JA. Central sleep apnea. Compr Physiol. 2013;3(1):141-63. https://doi.org/10.1002/cphy.c110057

16. Zieliński J, Koziej M, Mańkowski M, Sarybaev AS, Tursalieva JS Sabirov IS, et al. The quality of sleep and periodic breathing in healthy subjects at an altitude of 3,200 m. High Alt Med Biol. 2000;1(4):3316. https://doi.org/10.1089/15270290050502408

17. Krakow B, Krakow J, Ulibarri VA, Mclver ND. Frequency and accuracy or "RERA" and "RDI" terms in the Journal of Clinical Sleep Medicine from 2006 through 2012. J Clin Sleep Med. 2014;10(2):121-4. https:// doi.org/10.5664/jcsm.3432

18. Selim B. CON: Upper airway resistance syndrome does not exist as a distinct disease. J Dental Sleep Med. 2016;3(1):25-7. https://doi. org/10.15331/jdsm.5368

19. Asker M, Asker S, Kucuk U, Olgun HO. An overlooked cause of resistant hypertension: upper airway resistance syndrome preliminary results. Clinics (Sao Paulo). 2014;69(11):731-4. https:// doi.org/10.6061/clinics/2014(11)04

20. Palombini L, Lopes MC, Tufik S, Christian G, Bittencourt LR. Upper airway resistance syndrome: still not recognized and not treated. Sleep Sci. 2011;4(2):72-8 